
коронавирусной инфекции COVID-19

\author{
( С Митронин А.В., Апресян Н.А., Останина Д.А., Юрцева Е.Д. \\ Федеральное государственное бюджетное образовательное учреждение высшего образования \\ «Московский государственный медико-стоматологический университет имени А.И. Евдокимова» \\ Министерства здравоохранения Российской Федерации, Москва, Россия
}

\begin{abstract}
Резюме:
Цель. Установить взаимосвязь между наличием очагов хронической инфекции в полости рта и тяжестью течения респираторной коронавирусной инфекции, вызванной SARS-CoV-2.

Материалы и методы. Было проведено исследование 30 человек в возрасте от 18-22 лет, которые переболели коронавирусной инфекцией в легкой, средней или тяжелой степени тяжести. Была выполнена оценка стоматологического статуса пациентов с помощью основныхи дополнительных методов обследования, индекса КПУ, индекса РМА, индекса гигиены полости рта по Грин-Вермиллиону.

Результаты. В 1 группе среднее значение индекса КПУ составило 4,2, а во второй группе исследования индекс КПУ был в два раза выше и составил 7,8. Индекс РМА у пациентов 2 группы оказался достоверно выше (р>0.01) и составил 41,5\%. В группе 1 индекс РМА был равен 13,3\%. Было выявлено, что у 17\% респондентов контрольной группы и у 70\% опрошенных экспериментальной группы отмечалось эпизодическое обострение стоматологических заболеваний во время болезни COVID-19.

Выводы. Полученные данные свидетельствуют о достоверном наличии корреляционной зависимости между заболеваниями полости рта и степенью тяжести течения COVID-19. Следует рассматривать очаги хронической инфекции, а также плохую гигиену полости рта как факторы риска осложнений вирусных инфекций, в частности, тяжелой респираторной инфекции COVID-19.
\end{abstract}

Ключевые слова: COVID-19, коронавирусная инфекция, стоматологический статус пациента.

Статья поступила: 08.12.2020; исправлена: 31.01.2021; принята: 03.02.2021.

Конфликт интересов: Авторы декларируют отсутствие конфликта интересов.

Для цитирования: Митронин А.В., Апресян Н.А., Останина Д.А., Юрцева Е.Д. Взаимосвязь стоматологического статуса пациентов с тяжестью течения респираторной коронавирусной инфекции COVID-19. Эндодонтия today. 2021; 19(1):18-22. DOI: 10.36377/1683-2981-2021-19-1-18-22.

\title{
Correlation between oral health and severity of respiratory coronavirus infection COVID-19
}

\author{
(c) A.V. Mitronin, N.A. Apresian, D.A. Ostanina, E.D. Yurtseva \\ Federal State Budgetary Educational Institution of the Higher Education \\ "A.I. Yevdokimov Moscow State University of Medicine and Dentistry" \\ of the Ministry of Healthcare of the Russian Federation, Moscow, Russia
}

\begin{abstract}
:
Aim. To establish the association between the presence of chronic infection in oral cavity and the severity of SARSCoV-2 infection.

Materials and methods. The study was conducted among 30 people aged between18 and 22 who had had coronavirus infection from mild to severe cases. The assessment of oral health was carried out with main and additional examination methods, CFE index, PMA index, Greene, Wermillion oral hygiene index.

Results. In group 1, the average value of CFE index was 4.2, in the second group - CFE index was twice higher at 7.8 . PMA index in patients of group 2 was significantly higher $(p>0.01)$ and was at the level of $41.5 \%$. In group 1, the PMA index was $13.3 \%$. It was found that $17 \%$ of the respondents in the control group and $70 \%$ patients in the experimental group had an episodic exacerbation of dental diseases during COVID-19.

Conclusions. The data obtained indicates a correlation between oral diseases and the severity of COVID-19. It is necessary to consider that chronic infection in the oral cavity as well as poor oral hygiene can act as a risk of complications of viral infections, in particular, of COVID-19.
\end{abstract}

Keywords: COVID 19, coronavirus infection, oral health. 


\section{Исследования / Scientific researches}

Received: 08.12.2020; revised: 31.01.2021; accepted: 03.02.2021.

Conflict of interests: The authors declare no conflict of interests.

For citation: A.V. Mitronin, N.A. Apresian, D.A. Ostanina, E.D. Yurtseva. Correlation between oral health and severity of respiratory coronavirus infection COVID-19. Endodontics today. 2021; 19(1):18-22. DOI: 10.36377/1683-2981-2021-191-18-22.

\section{АКТУАЛЬНОСТЬ}

31 декабря 2019 года Всемирная организация здравоохранения (ВОЗ) была проинформирована о 27 случаях пневмонии неизвестной этиологии в городе Ухань, Китай. К 7 января 2020 года возбудитель вируса был идентифицирован как SARS-CoV-2, вызывающий заболевание COVID-19.

На сегодняшний день проведено множество исследований, посвященных COVID-19, и информация постоянно пополняется. Было доказано, что спектр проявления симптомов инфекции варьирует от легкой степени до тяжелой в зависимости от возраста, пола и сопутствующих заболеваний (сахарный диабет, гипертония, ожирение и сердечнососудистые заболевания). Перед медицинским сообществом стоит задача определить, почему пациенты страдают от COVID-19 в разной степени тяжести. Несмотря на то, что пожилые пациенты с сопутствующими заболеваниями имеют наибольшее количество осложнений и высокий уровень смертности, все еще существует высокая доля молодых и здоровых пациентов без выявленных факторов риска, которые имеют грозные осложнения болезни COVID-19.

При респираторно-вирусных инфекциях зачастую возникает предрасположенность пациентов к присоединению бактериальных инфекций, что ведет к нарастанию тяжести заболевания и даже смертности. Гипотетически, неудовлетворительный стоматологический статус пациентов может являться риском инфицирования легких бактериальной инфекцией полости рта, а также быть причиной развития поствирусных бактериальных осложнений.

Легкие человека, аналогичные ротовой полости, часто называют «экологическим сообществом комменсальных, симбиотических и патогенных организмов» [1]. Иммиграция и элиминация микроорганизмов между ротовой полостью и легкими осуществляется постоянно, что обеспечивает здоровое распределение микробиоты. Однако, это равновесие может резко измениться во время болезни, что приведет к чрезмерному росту микробного консорциума и, как следствие, повреждению легких.

В настоящем исследовании была осуществлена попытка определить, существует ли взаимосвязь между хронической бактериальной нагрузкой при заболеваниях полости рта и коронавирусной инфекцией, вызванной SARS-CoV-2.

Мы предполагаем, что наличие хронических очагов инфекций в полости рта при заболеваниях твердых тканей зубов, пульпы, периодонта и пародонта можно считать факторами, которые определяют тяжесть течения COVID-19. На сегодняшний день в литературных источниках данные корреляции тяжести течения COVID-19 и наличия хронических очагов инфекции в полости рта освещены недостаточно и имеют ограниченный характер.

\section{ЦЕЛЬ ИССЛЕДОВАНИЯ}

Установить взаимосвязь между наличием очагов хронической инфекции в полости рта и тяжестью те- чения респираторной коронавирусной инфекции, вызванной SARS-CoV-2.

\section{МАТЕРИАЛ И МЕТОДЫ}

Дизайн настоящей исследовательской работы состоял из нескольких этапов:

- Разработать специализированную анкету опроса стоматологического больного, перенесшего коронавирусную инфекцию.

- Провести обследование полости рта и определить стоматологический статус пациентов, переболевших коронавирусной инфекцией.

- Выявить динамику стоматологических жалоб в период болезни коронавирусной инфекцией.

- Выявить наличие корреляционной зависимости тяжести течения COVID-19 и стоматологического статуса COVID-положительных пациентов.

В клиническое исследование было включено 30 пациентов без сопутствующей патологии, однородных по возрасту (20-/+ 2 года), обоих полов. Все пациенты переболели коронавирусной инфекции в легкой, средней и тяжелой степени тяжести. Критерием формирования групп на последующих этапах исследования являлась тяжесть течения COVID-19. Все пациенты были разделены на две группы в зависимости от тяжести течения COVID-19: в 1 (контрольную) группу были включены 17 человек, переболевших коронавирусной инфекцией в легкой степени тяжести; в 2 (экспериментальную) группу были включены 13 человек, переболевшие COVID-19 в средней и тяжелой степени тяжести.

В ходе исследования была разработана специализированная анкета для пациентов, переболевших коронавирусной инфекции, с целью определения стоматологического статуса и течения COVID-19 (рисунок 1).

Всем пациентам было проведено комплексное обследование по следующим параметрам: обследование полости рта (основные методы обследования: опрос, осмотр, зондирование, перкуссия, пальпация; дополнительные методы обследования: ортопантомографическое исследование (ОПТГ); индекс КПУ; индекс гигиены полости рта по Грин-Вермиллиону; оценка тканей пародонта; индекс РМА.

Результаты исследования были статистически обработаны с помощью программ Statistica 6.0 и Microsoft Excel c вычислением среднего арифметического значения, ошибки средней арифметической величины. Для выявления различий использовали t-критерий Стьюдента. Различия считали достоверными при $р>0,05$.

\section{РЕЗУЛЬТАТЫ ИССЛЕДОВАНИЯ}

При проведении анкетирования 87\% опрошенных первой группы исследования отметили, что регулярно посещают стоматолога в профилактических целях. Во второй группе только 34\% опрошенных регулярно обращались к стоматологу. 12\% респондентов в 1 группе исследования отмечали жалобы различного характера, связанные с состоянием полости рта, а также отмечали обострение стоматологических заболеваний в период болезни COVID-19. Во второй группе пациентов более $60 \%$ опрошенных отметили повышение 


\section{0 Исследования / Scientific researches}

чувствительности зубов и появление болезненности при жевании. Было выявлено, что у $17 \%$ респондентов контрольной группы и у 70\% опрошенных экспериментальной группы отмечалось эпизодическое обострение стоматологических заболеваний во время болезни COVID-19.

\begin{tabular}{|c|c|}
\hline \multicolumn{2}{|c|}{ 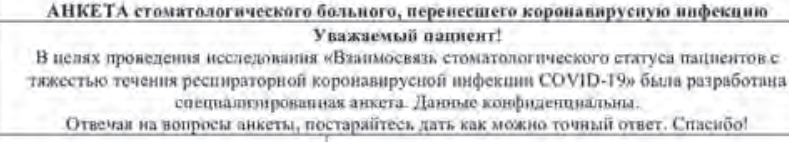 } \\
\hline \multicolumn{2}{|l|}{ ФHó: } \\
\hline \multicolumn{2}{|l|}{ Дапа рождения: } \\
\hline ВОПРОСЫ & ОТВЕТЫ \\
\hline 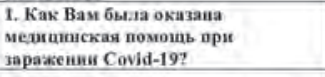 & Амбулаторноссташіоіарно \\
\hline \multicolumn{2}{|l|}{ 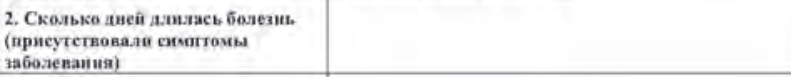 } \\
\hline \multicolumn{2}{|l|}{ 3. Каминческие шрапвления: } \\
\hline Лихорадка & ДА/HЕТ \\
\hline Слабость & ДАНHET \\
\hline Головная боль & ДА/HET \\
\hline Боп в горіе & ДА/HET \\
\hline Дизрек. тошнота, ряота & ДА/HET \\
\hline Каmель & ZAAHET \\
\hline Потеря вкуса, обоняния & ДA/HET \\
\hline 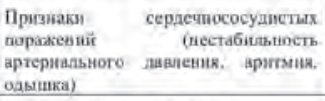 & ДА/HET \\
\hline Сатурашия кислорода $<93 \%$ & ДA/HET \\
\hline $\begin{array}{l}\text { Присоединешие } \\
\text { бактериальной инфекиии }\end{array}$ & ДA/HET \\
\hline 4. Наличие осаожнеинй & ДА/HET \\
\hline \multicolumn{2}{|l|}{ есаи да, то какие? } \\
\hline 5. Тнжесть течения Covid-19 & 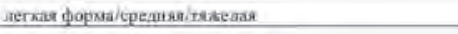 \\
\hline \multicolumn{2}{|l|}{$\begin{array}{l}\text { 6. Как часто Вы обрашастесь к } \\
\text { стоматолегу? }\end{array}$} \\
\hline 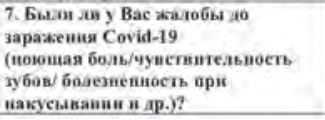 & ДАНHET \\
\hline \multicolumn{2}{|l|}{7.1 Есан бы.ан жалебы, тө какше? } \\
\hline $\begin{array}{l}\text { 8. Как пзмевнлась динамика жалоб } \\
\text { uри Covid-19? }\end{array}$ & Обострение/без нзменений \\
\hline \multicolumn{2}{|l|}{ Дата: } \\
\hline Подписе: & \\
\hline
\end{tabular}

Рис. 1. Анкета для сбора анамнеза стоматологического пациента, перенесшего коронавирусную инфекцию

Fig. 1. Questionnaire for COVID-19 patient's dental history

Таблица 1. Результаты стоматологического осмотра пациентов исследуемых групп Table 1. The results of dental examination in patients between groups

\begin{tabular}{|c|c|c|c|c|}
\hline Группа & N & $\begin{array}{c}\text { Сред. } \\
\text { значение }\end{array}$ & Медиана & $\begin{array}{c}\text { Ст. ошиб- } \\
\text { ка ср. }\end{array}$ \\
\hline \multicolumn{5}{|c|}{ Индекс КПу } \\
\hline 1 (контрольная) & 17 & 5,8823 & 6,0000 & 0,4011 \\
\hline 2 (экспериментальная) & 13 & 12,2000 & 13,0000 & 0,6845 \\
\hline Индекс гигиены полости рта по Грин-Вермиллиону \\
\hline 1 (контрольная) & 17 & 1,1429 & 1,1000 & 0,0804 \\
\hline 2 (экспериментальная) & 13 & 2,5666 & 2,5000 & 0,0974 \\
\hline \multicolumn{5}{|c|}{ Индекс РМА } \\
\hline 1 (контрольная) & 17 & 13,3117 & 13,000 & 1,0256 \\
\hline 2 (экспериментальная) & 13 & 79,6000 & 83,000 & 3,6473 \\
\hline
\end{tabular}

При сравнении результатов стоматологического осмотра были выявлены статистически значимые отличия состоянии полости рта у пациентов исследуемых групп ( $>$ > 0,05), которые представлены в таблице 1.

На рис. 2 представлено сравнение индексов КПУз в 1 и 2 группах. В 1 группе среднее значение индекса КПУз составило 5,8, а во второй группе индекс был в два раза выше - 12,2.

Согласно данным индекса гигиены полости рта по Грин-Вермиллиону, твердые зубные отложения были выявлены в обеих группах. Однако, следует отметить, что уровень гигиены у пациентов 1 группы был выше и

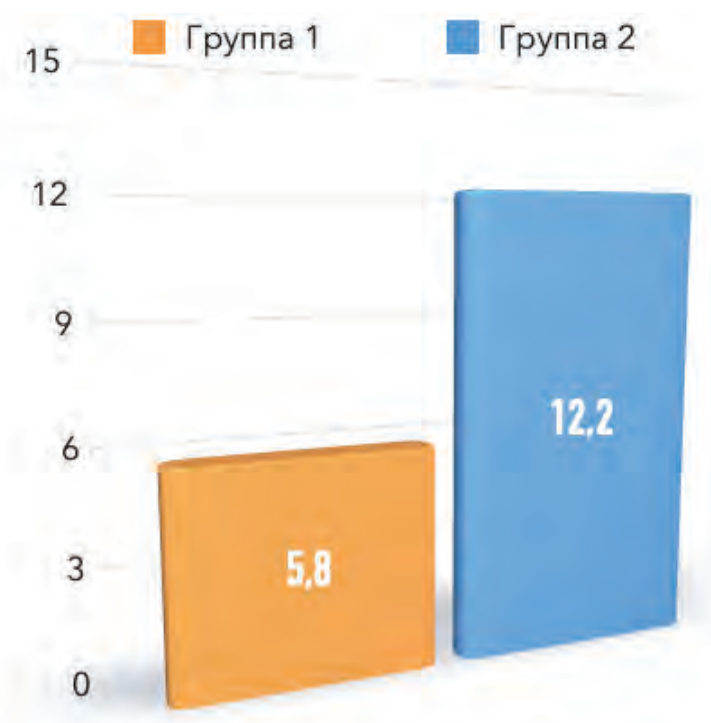

Среднее значение инАекса КПУз

Рис. 2. Сравнение результатов индекса КПУз в группах исследования Fig. 2. A comparison of the CFE index results between groups

5

Группа 1

Группа 2
3

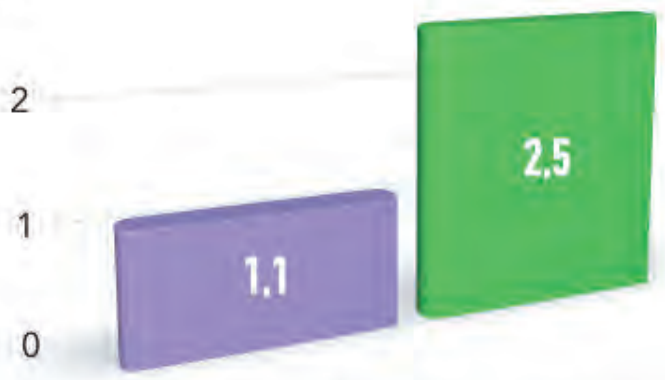

Среднее значение индекса гигиены полости рта по Грин-Вермимлиону

Рис. 3. Сравнение значений индекса ГринВермиллионна в группах исследования

Fig. 3. A comparison of Green-Vermillion oral hygiene index between groups 


\section{Исследования / Scientific researches}

составил в среднем 1,1. Во второй группе исследования данный показатель был равен 2,5, что соответствует плохому уровню гигиены полости рта. Также было выявлено, что у 70\% пациентов 2 группы отмечается большая склонность к образованию твёрдых и мягких зубных отложений (рис. 3).

Для оценки состояния тканей пародонта использовался индекс РМА, объективно отражающий состояние пародонта. Индекс РМА у пациентов 2 группы оказался достоверно выше (р>0.01) и составил 85,5\%. В группе 1 индекс РМА был равен 13,3\%. Кроме того, у 62\% пациентов из 2 группы исследования были выявлены симптомы заболеваний тканей пародонта (рис. 4).

По результатам ОПТГ, только у $12 \%$ пациентов контрольной группы исследования были выявлены патологические изменения в области периапикальных тканей зубов. В экспериментальной группе исследования у 45\% обследованных наблюдались очаги разрежения костной ткани в области верхушек корней зубов при рентгенологическом исследовании.

\section{ОБСУЖДЕНИЕ}

Тяжелое и среднее течение коронавирусной инфекции наблюдалось в основном у пациентов, имеющих заболевания твердых тканей зубов, пульпы и пародонта. Это может быть связано с высокой бактериальной нагрузкой организма и хронической усталостью иммунной системы.

Вдыхание микроорганизмов (P. gingivalis, F. nucleatum, P. intermedia), содержащихся в полости рта и связанных с такими заболеваниями, как кариес и его осложнения, периодонтит и пародонтит, осложняют течение респираторной вирусной инфекции [2]. Пародонтит и кариес - два наиболее распространенных заболевания полости рта, связанных с дисбалансом микробиоты полости рта.

Хорошая гигиена полости рта признана средством профилактики инфекций дыхательных путей у пациентов, особенно у людей старше 70 лет [3]. Сахарный диабет, артериальная гипертензия и болезни сердечно-сосудистой системы, повышающие риск осложнений COVID-19, также ранее были ассоциированы с дисбалансом микробиологической среды полости рта при повышении содержания F. nucleatum, P. intermedia и P. Gingivalis и прогрессированием заболеваний пародонта. Это служит основанием предположить наличие взаимосвязи между плохим состоянием здоровья полости рта и тяжестью течения COVID-19 [4].

Сенсибилизация эпителия дыхательных путей и гематогенное распространение провоспалительных цитокинов при заболеваниях полости рта могут усиливать системное воспаление. Заболевания дыхательной системы могут также усугубляться под действием белков острой фазы воспаления, которые продуцируются печенью и имеют системное влияние на весь организм в целом [5]. Это подтверждается тем, что у пациентов с тяжелым течением инфекции COVID-19 проявляются системные симптомы воспаления, а в анализах крови определяются высокие уровни интерлейкина-6, интерлейкина-2, интерлейкина-10, фактора некроза опухоли и С-реактивного белка [6].

В рандомизированном контролируемом исследовании в Японии изучалось взаимосвязь между уходом за полостью рта и частотой развития пневмонии, а так-
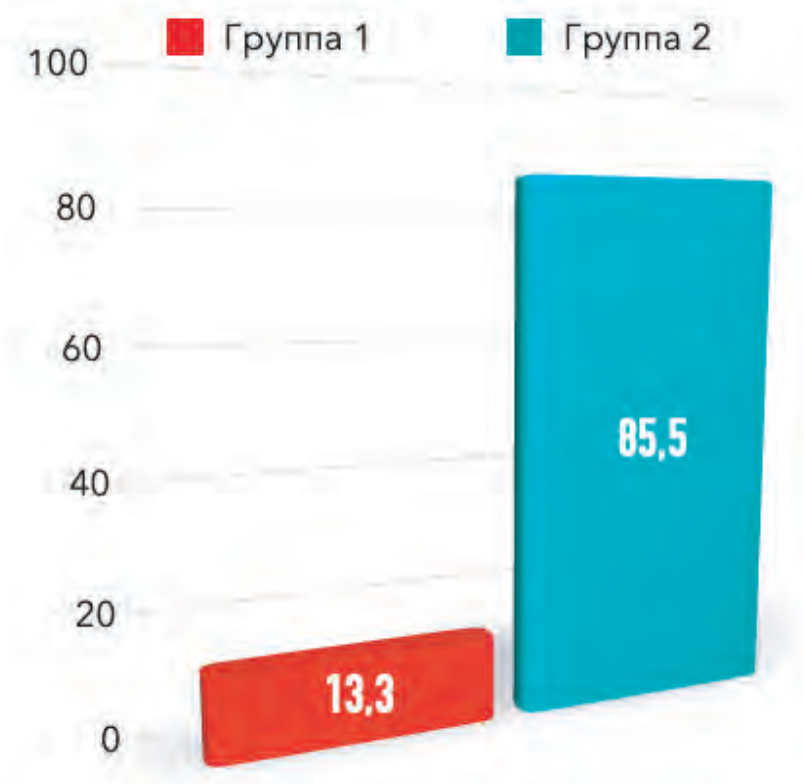

СРеАнее значение инАекса РМА

\section{Рис. 4. Сравнение значение индекса PMA в группах исследования}

Fig. 4. A comparison of the PMA index results between groups

же связанной с ней смертностью. 470 пациентов проводилась профессиональная гигиена полости рта после каждого приема пищи, в то время как в контрольной группе пациентов гигиена полости рта проводилась непосредственно испытуемым. В контрольной группе исследования 19\% пациентов болели пневмонией, а в экспериментальной группе - $11 \%$ пациентов. Более того, уровень смертности от постпневмонических осложнений в контрольной группе был почти вдвое выше, чем в группе пациентов, которым осуществлялся уход за полостью рта [7]. Связь между стоматологическим статусом и риском развития острых респираторных вирусных инфекций была также установлена в других фундаментальных исследованиях [8,9]. Более того, было доказано, что эффективная гигиена полости рта значительно снижает частоту ИВЛ-ассоциированной пневмонии у пациентов в отделениях интенсивной терапии [10].

\section{выводы}

На основании данных, полученных в результате настоящего исследования, была выявлена достоверная корреляционная зависимость между заболеваниями полости рта и степенью тяжести течения респираторной инфекции COVID-19. У 93\% пациентов, перенесших вирусную инфекцию в средней и тяжелой степени, были обнаружены заболевания тканей пульпы, периодонта и пародонта. Таким образом, рекомендуется рассматривать очаги хронической инфекции, а также плохую гигиену полости рта как фактор риска осложнения вирусных инфекций, в частности, COVID-19. Улучшение гигиены полости рта, профилактика развития кариеса и его осложнений и болезней пародонта могут сыграть важную роль как в снижении риска заражения коронавирусной инфекции, так и в профилактике развития тяжелых осложнений. 


\section{2 Исследования / Scientific researches}

\section{СПИСОК ЛИТЕРАТУРЫ/ REFERENCES:}

1. Mathieu E, Escribano-Vazquez U, Descamps D et al. Paradigms of Lung Microbiota Functions in Health and Disease, Particularly, in Asthma. Front Physiol 2018; DOI: 10.3389/fphys.2018.01168

2. Scannapieco F A, Genco R J. Association of periodontal infections with atherosclerotic and pulmonary diseases. J Periodontal Res 1999; 34: $340-345$.

3. Sjögren $P$, Nilsson $E$, Forsell $M$, Johansson $O$, Hoogstraate J. A systematic review of the preventative effect of oral hygiene on pneumonia and respiratory tract infection in elderly people in hospitals and nursing homes: effect estimates and methodological quality of randomised controlled trials. J Am Geriatr Soc 2008; 56: 2124-2130.

4. Takahashi K, Nishimura F, Kurihara M et al. Subgingival microflora and antibody responses against periodontal bacteria of young Japanese patients with type 1 diabetes mellitus. J Int Acad Periodontol 2001; 3: 104-111.
5. Gomes-Filho IS, Seixas da Cruz S, Trindade S C et al. Periodontitis and respiratory diseases: a systematic review with meta-analysis. Oral Dis 2020; 26: 439-446.

6. Gong J, Dong H, Xia S Q et al. Correlation Analysis Between Disease Severity and Inflammation-related Parameters in Patients with COVID-19 Pneumonia. 2020.(accessed June 2020).

7. Yoneyama T, Yoshida M, Ohrui T et al. Oral care reduces pneumonia in older patietns in nursing homes. J Am Geriatr Soc 2002; 50: 430-433.

8. Scannapieco F A. Role of Oral Bacteria in Respiratory Infection. J Periodontol 1999; 70: 793-802.

9. Abe S, Ishihara K, Adachi, et al. Professional oral care reduced influenza infection in elderly. Arch Gerontol Geriatr 2006; 43: 157-164.

10. Mori H, Hirasawa $\mathrm{H}$, Oda S, et al. Oral Care reduced incidence of ventilator associate pneumonia in ICU populations. Intensive Care Med 2006; 32: 230-236.

\section{ИНФОРМАЦИЯ ОБ АВТОРАХ:}

Митронин А.В. - профессор, доктор медицинских наук, декан стоматологического факультета МГМСу, заведующий кафедрой, Заслуженный врач PФ, ORCID ID: 0000-0002-3561-6222.

Апресян Н.А. - студентка 4 курса.

Останина Д.А. - ассистент, ORCID ID: 0000-0002-5035-5235.

Юрцева Е.Д. - ассистент, кандидат медицинских наук.

Кафедра кариесологии и эндодонтии. Федеральное государственное бюджетное образовательное учреждение высшего образования «Московский государственный медико-стоматологический университет имени А.И. Евдокимова» Министерства Здравоохранения Российской Федерации, Москва, Россия.

\section{AUTHOR INFORMATION:}

A.V. Mitronin - professor, Doctor of Medical Sciences, Dean of the Faculty of Dentistry, Head of the Department, Honored Doctor of Russian Federation, ORCID ID: 0000-0002-3561-6222.

N.A. Apresian - student.

D.A. Ostanina - assistant, ORCID ID: 0000-0002-5035-5235.

E.D. Yurtseva - assistant, PhD.

Department of Cariology and Endodontics. A.I. Yevdokimov Moscow State University of Medicine and Dentistry, Moscow, Russia.

Координаты для связи с авторами / Coordinates for communication with authors: Апресян H.A. / N.A. Apresian, E-mail: nelia.apresyan@yandex.ru 